\title{
Safety evaluation of four faba bean extracts used as dietary supplements in grass carp culture based on hematological indices, hepatopancreatic function and nutritional condition
}

\author{
Lingling Ma ${ }^{\text {Equal first author, } 1,2}$, Gen Kaneko ${ }^{\text {Equal first author, } 3}{ }^{3}$, Jun Xie ${ }^{1}$, Guangjun Wang ${ }^{1}$, Zhifei Li ${ }^{1}$, Jingjing Tian ${ }^{1}$, Kai Zhang \\ ${ }^{1}$, Yun Xia ${ }^{1}$, Wangbao Gong ${ }^{1}$, Haihang Li $^{4}$, Ermeng Yu ${ }^{\text {Corresp. } 1}$ \\ ${ }^{1}$ Key Laboratory of Tropical \& Subtropical Fishery Resource Application \& Cultivation, Pearl River Fisheries Research Institute of CAFS, Guangzhou, China \\ 2 National Demonstration Center for Experimental Fisheries Science Education, Shanghai Ocean University, Shanghai, China \\ ${ }^{3}$ School of Arts \& Sciences, University of Houston-Victoria, Victoria, Texas, United States \\ 4 Guangdong Provincial Key Lab for Plant Development, School of Life Sciences, South China Normal University, Guangzhou, China
}

Corresponding Author: Ermeng Yu

Email address: boyem34@hotmail.com

Faba bean (Vicia faba, FB) is known to improve the texture of fish meat but retards growth possibly by inducing hemolysis, hepatopancreas damage, and metabolic disorder. In this study, we used ultrasonic processing to isolate four FB extracts (water extract, alcohol extract, proteins, and residues) and examined their beneficial and detrimental effects. These extracts were separately mixed with commercial feed and fed to grass carp (Ctenopharyngodon idellus) using whole FB and commercial feed as controls. After fish were fed one of the six experimental diets for $50 \mathrm{~d}$ and $100 \mathrm{~d}$, we evaluated the growth and hematological parameters, activities of metabolic enzymes, hepatopancreatic histology and oxidative response, and lipid metabolism. Results showed that both whole FB and FB residues caused growth retardation and hepatopancreas damage $(P<0.05)$, whereas growth performance was improved in the FB water and alcohol extract groups compared to the whole FB group. Although the FB water extract negatively affected the number and morphological parameters of red blood cells $(P<0.05)$, the hematological damage was less pronounced than that of the whole FB group. Excessive hepatopancreatic fat accumulation was found in the whole FB, FB alcohol extract, and FB residues groups. Moreover, serious hepatopancreas damages were observed in the FB residues group. These results suggest that the beneficial and detrimental components of FB were successfully separated in the four extracts, and the FB water extract would be the best choice for grass carp culture in terms of growth performance and health. The safety evaluation of the four FB extracts would facilitate further application of FB in aquatic feed. 


\section{Safety evaluation of four faba bean extracts used as}

2 dietary supplements in grass carp culture based on

3 hematological indices, hepatopancreatic function and

4 nutritional condition

5

6

7

Ling-Ling Ma ${ }^{1,2 a}$, Gen Kaneko ${ }^{3 a}$, Jun Xie ${ }^{1}$, Guang-Jun Wang ${ }^{1}$, Zhi-Fei Li ${ }^{1}$, Jing-Jing Tian ${ }^{1}$, Kai Zhang ${ }^{1}$, Yun $\mathrm{Xia}^{1}$, Wang-Bao Gong ${ }^{1}$, Hai-Hang $\mathrm{Li}^{4}$, Er-Meng $\mathrm{Yu}^{1 *}$

${ }^{1}$ Key Laboratory of Tropical \& Subtropical Fishery Resource Application \& Cultivation, Pearl River Fisheries Research Institute of CAFS, Guangzhou, China

${ }^{2}$ National Demonstration Center for Experimental Fisheries Science Education, Shanghai Ocean University, Shanghai, China

${ }^{3}$ School of Arts \& Sciences, University of Houston-Victoria, Victoria, Texas, United States

${ }^{4}$ Guangdong Provincial Key Lab for Plant Development, School of Life Sciences, South China Normal University, Guangzhou, China

Corresponding Author:

Er-Meng Yu

Xingyu Road No.1, Guangzhou 510380, China

Email address: boyem34@hotmail.com

${ }^{a}$ These authors contributed equally to this work. 


\section{ABSTRACT}

32 Faba bean (Vicia faba, FB) is known to improve the texture of fish meat but retards growth possibly by inducing hemolysis, hepatopancreas damage, and metabolic disorder. In this study, we used ultrasonic processing to isolate four FB extracts (water extract, alcohol extract, proteins, and residues) and examined their beneficial and detrimental effects. These extracts were separately mixed with commercial feed and fed to grass carp (Ctenopharyngodon idellus) using whole FB and commercial feed as controls. After fish were fed one of the six experimental diets for $50 \mathrm{~d}$ and $100 \mathrm{~d}$, we evaluated the growth and hematological parameters, activities of metabolic enzymes, hepatopancreatic histology and oxidative response, and lipid metabolism. Results showed that both whole FB and FB residues caused growth retardation and hepatopancreas damage $(P<0.05)$, whereas growth performance was improved in the FB water and alcohol extract groups compared to the whole FB group. Although the FB water extract negatively affected the number and morphological parameters of red blood cells $(P<0.05)$, the hematological damage was less pronounced than that of the whole FB group. Excessive hepatopancreatic fat accumulation was found in the whole FB, FB alcohol extract, and FB residues groups. Moreover, serious hepatopancreas damages were observed in the FB residues group. These results suggest that the beneficial and detrimental components of FB were successfully separated in the four extracts, and the FB water extract would be the best choice for grass carp culture in terms of growth performance and health. The safety evaluation of the four FB extracts would facilitate further application of FB in aquatic feed.

Subjects: Aquaculture, Fisheries and Fish Science, Feed Nutrition

Keywords: Ctenopharyngodon idellus, Vicia faba, Extracts, Safety evaluation, Hepatopancreas, 55 Metabolism enzymes 
56

57

58

59

60

61

62

63

64

65

66

67

68

69

70

71

72

73

74

75

76

77

78

79

80

81

82

83

84

85

86

87

88

89

90

91

92

93

94

95

\section{INTRODUCTION}

Crisp grass carp (Ctenopharyngodon idellus C.et V), a high-quality grass carp fed solely on faba bean (Vicia faba) for 90-120 days, has been protected as the "China Geographical Indication Product" and its fillet products are exported to North America (Ma et al., 2020). Compared with ordinary grass carp, crisp grass carp has unique muscle qualities, such as increased hardness and springiness (Lin et al., 2009; Xu et al., 2020; Yu et al., 2020). As a potential protein source, faba bean has also been used to partially replace animal protein sources in human diets (Multari et al., 2015). However, faba bean is known to cause growth retardation and organ damages in fish ( $\mathrm{Li}$ et al., 2018; Macarulla et al., 2001; Tian et al., 2019; Zhang et al., 2015), thus requiring further research on its beneficial and detrimental effects.

Many previous studies have shown that long-term or excessive intake of faba bean has various detrimental effects on fish such as hemolysis, hepatopancreas damage, and metabolic disorders. The blockage of the blood circulation system is one of the main negative effects of faba bean feeding in grass carp culture ( $T a n \& L i, 2005$ ), and severe damages to the intestinal tract, head kidney, hepatopancreas, and serum antioxidant enzymes have also been reported in this species (Gan et al., 2017; Chen et al., 2019). The hepatopancreatic steatosis caused by long-term ingestion of faba bean may be related to the increased de novo synthesis of fatty acids, enhanced oxidative stress, and mitochondrial damage (Fu et al., 2020). Although a certain level of protein concentrate from faba bean can be efficiently utilized as a dietary protein source for Atlantic salmon (Salmo salar) (De Santis et al., 2016), diets containing more than 10\% of faba bean have adverse effects on growth performance, hematological parameters, and serum biochemical parameters in the beluga (Huso huso) juveniles (Soltanzadeh et al., 2016). However, it is unclear which components of faba bean are responsible for these organ damages.

Our previous study isolated four types of faba bean extracts - FB water extract, FB alcohol extract, FB proteins, and FB residues - and examined their effects on the muscle quality of grass carp including increased hardness, collagen contents, and fiber density (Ma et al., 2020). The aim of the present study is to test the effects of these four FB extracts on the growth, hematology, hepatopancreatic function, and lipid metabolism of grass carp, in a 100-d feeding trial using six diets including commercial feed, whole faba bean (FB), and the four FB extract feeds (FB water extract feed, FB alcohol extract feed, FB proteins feed, and FB residues feed).

\section{MATERIALS AND METHODS}

\section{Experimental feeds}

Four FB extracts (FB water extract, FB alcohol extract, FB proteins, and FB residues) were obtained through methods in our previous study (Ma et al., 2020). In short, shelled FB was ground into 60-um powder, mixed with distilled water, and adjusted $\mathrm{pH}$ to 9.0. After ultrasonic processing and followed by centrifugation, the FB water extract was obtained by concentrating the water supernatant. The precipitates were dried, and the FB proteins were thus obtained. After 
96 the residues from the first centrifugation were resuspended in ethanol, the FB alcohol extract was

97 obtained by concentrating the ethanol extract, with the remaining precipitate representing the FB

98 residues. To maintain the activities of heat-sensitive components, moderate temperature $(<55$

$99{ }^{\circ} \mathrm{C}$ ) was used throughout the extracting and formulating processes. In addition to the four

100 experimental feeds (each weighing $16 \mathrm{~kg}$ ) including FB water extract feed, FB alcohol extract

101 feed, FB proteins feed, and FB residues feed, we used whole FB and commercial feed as controls

102 (Ma et al., 2020). The nutritional components of these extracts and controls are shown in Table

1031.

104

105

\section{Fish culture}

Grass carp with a body weight of $750 \pm 36 \mathrm{~g}$ were randomly allocated into six groups with two tanks per group and a density of eight individuals per tank. The fish were fed one of the six diets (four FB extracts feeds, commercial feed, or whole FB) at 9:00 am and 4:00 pm each day for 100 days, and the feed amount for each day was $1 \%-2 \%$ of fish weight. The water temperature was kept at $25-30{ }^{\circ} \mathrm{C}$, $\mathrm{pH}$ was $6.5-7.5$, and dissolved oxygen (DO) was above $5.0 \mathrm{mg} / \mathrm{L}$.

\section{Sampling procedures}

On $50 \mathrm{~d}$ and $100 \mathrm{~d}$, three grass carp were sampled from each group. The fish were anesthetized with $\mathrm{pH}$-buffered tricaine methanesulfonate $(250 \mathrm{mg} / \mathrm{L})$, and $8 \mathrm{~mL}$ of blood per fish was collected from the vertebral blood vessel. Three $\mathrm{mL}$ of blood was placed in an anticoagulant vessel containing EDTAK2 and used for hematologic analyses with an automatic blood cell analyzer (BC-5000, Shenzhen mindray bio-medical electronics Co. Ltd, Shenzhen, China). After standing for $4 \mathrm{~h}$, serum was separated from the remaining $5 \mathrm{~mL}$ of blood by centrifugation at $3500 \mathrm{r} / \mathrm{min}$ for $10 \mathrm{~min}$ and immediately stored at $-80^{\circ} \mathrm{C}$ for further biochemical analyses. Next, the body weight, body length, and the weight of the viscera, hepatopancreas, and mesenteric fat were measured to determine growth performance. The hepatopancreas $\left(2 \mathrm{~mm}^{3}\right)$ was fixed in Bouin's reagent for $18 \mathrm{~h}$ and used for hematoxylin and eosin (H\&E) staining. A small piece of the hepatopancreas was also sampled for enzymatic measurements.

The experimental protocols used in this study were approved by the Animal Ethics Committee of the Guangdong Provincial Zoological Society, China, under permit number GSZAW012.

\section{Blood biochemical analyses}

The serum lipid metabolism was tested by measuring the total cholesterol (TC), triglyceride (TG), high density lipoprotein cholesterol (HDL-C), and low density lipoprotein cholesterol (LDL-C) levels using an automatic biochemical analyzer (7020, Hitachi high-tech, Tokyo, Japan). The activities of the serum enzymes, including glutamic oxalacetic transaminase (GOT), glutamic-pyruvic transaminase (GPT), alkaline phosphatase (AKP) and peroxidase (POD), were also measured by using GOT, GPT, AKP and POD reagent kits (Jiancheng, Nanjing, China), respectively. Absorbance was detected according to our previous methods (Ma et al., 2020). 


\section{Hepatopancreatic enzyme activity measure}

The hepatopancreatic lipid metabolism was assessed by measuring TC and TG levels and the activities of GPT, GOT, AKP and POD. Antioxidant parameters including superoxide dismutase (SOD), total glutathione (T-GSH), oxidative glutathione (GSSH), hydrogen peroxide $\left(\mathrm{H}_{2} \mathrm{O}_{2}\right)$, nicotinamide adenine dinucleotide (NADPH), and POD were also measured by our previous methods (Ma et al., 2020). The hepatopancreas was homogenized in nine volumes of saline per gram using the Tissuelyser-24 automatic sample rapid grinding machine (Jingxing Instruments, Shanghai, China), centrifuged at $3500 \mathrm{r} / \mathrm{min}$ for $10 \mathrm{~min}$ at $4{ }^{\circ} \mathrm{C}$, and the resulting supernatant was used for the analysis. To measure T-GSH and GSSH, four volumes of saline were used to prepare the hepatopancreatic homogenate.

\section{Hepatopancreatic histology}

Hematoxylin and eosin (H\&E) staining of hepatopancreas samples were performed as described previously (Ma et al., 2020). The stained slides of hepatopancreas samples from different groups were observed for histological analyses.

\section{Data analyses}

The data were analyzed using the SPSS 23 software (SPSS Inc., Chicago, IL, USA). The results are shown as "Mean \pm SE." All the assessed variables were subjected to the analysis of variance (ANOVA) followed by Duncan's test to determine the existence of significant differences between groups $(P<0.05)$.

\section{RESULTS}

\section{Growth parameters}

The growth parameters in different groups are shown in Table 2 . On $50 \mathrm{~d}$, the weight gain rates (WGR) of the FB water extract group was higher than that of the control group $(P<0.05)$, while the WGR, visceral somatic indexes (VSI), and hepatopancreas somatic index were the lowest in the FB residues group $(P<0.05)$. On $100 \mathrm{~d}$, the WGR of the FB water extract group was higher compared with the control, but the WGR of the whole FB and FB residues groups were the lowest $(P<0.05)$. These two groups also displayed a lower condition factor. The VSI and abdominal fat index tended to fluctuate with some significant differences on $50 \mathrm{~d}$, but there was no significant difference for the two parameters on $100 \mathrm{~d}(P>0.05)$.

\section{Hematological analyses}

To evaluate the morphology and function of blood cells, we chose several parameters, shown in Table 3, such as red blood cell count (RBC), hematocrit (HCT), hemoglobin (HGB), and white blood cell count (WBC) (see Discussion for rationale). On $50 \mathrm{~d}$, compared with the control group, only the FB water extract group showed a slightly lower level in RBC. Other three FB extracts and whole FB groups did not show significant difference in RBC. The FB and FB water 
extract groups had lower levels of RBC, HCT and HGB compared with the FB alcohol extract group on $100 \mathrm{~d}(P<0.05)$. There were no significant differences in the WBC among these groups $(P>0.05)$. In the FB residues group, the number (NEU\#) and percentage (NEU\%) of neutrophils were higher than those of the other groups on $100 \mathrm{~d}(P<0.05)$. There were no significant differences in other hematological parameters among the six groups $(P>0.05)$.

\section{Serum lipid and nutritional parameters}

Serum lipid metabolism parameters are shown in Fig. 1. On $50 \mathrm{~d}$, the TC, TG, and HDL-C contents were the highest in the control group and the lowest in the FB residues group $(P<0.05)$ (Fig. 1A, B and C). In terms of LDL-C content, the FB and FB water extract groups showed the highest levels, while the FB residues group showed the lowest $(P<0.05)$ (Fig. 1D). On $100 \mathrm{~d}$, both the TG and HDL-C contents were the lowest in the FB and FB residues groups $(P<0.05)$ (Fig. 1B and D). Both the TC and LDL-C contents of the whole FB group were higher than those of other groups on $100 \mathrm{~d}$. The four FB extract groups had significantly lower levels of TC and LDL-C than the control group $(P<0.05)$ (Fig. 1A and C).

Changes in serum enzymes are shown in Fig. 2. There were no significant differences in the GOT and AKP activities among groups on $50 \mathrm{~d}(P>0.05)$. However, on $100 \mathrm{~d}$, the GOT activities of the FB and FB protein groups were lower than those of the control and whole FB groups, while the AKP activities of the FB alcohol extract, water extract and protein groups were higher than those of the control group $(P<0.05)$. On $50 \mathrm{~d}$, the GPT activity was the highest in the FB protein group and then in the FB alcohol extract group $(P<0.05)$, while on $100 \mathrm{~d}$ it was the highest in the FB alcohol extract group $(P<0.05)$ (Fig. 2A). The POD activity of the FB proteins group was higher than those of the other groups on $50 \mathrm{~d}$ and $100 \mathrm{~d}$, respectively $(P<$ 0.05) (Fig. 2B, C and D).

\section{Hepatopancreatic lipid and metabolic parameters}

The TC and TG contents were also observed in the hepatopancreas along with the AKP, GOT, GPT and POD activities (Fig. 3). On 100 d, the TC contents of the FB water and FB alcohol groups were higher than those of the other groups (Fig. 3A), while the TG contents of the whole FB group were also higher than those of other groups $(P<0.05)$ (Fig. 3B). This phenomenon might be related to the normal developmental process where grass carp starts to accumulate visceral fat around $60 \mathrm{~d}$ (Tian et al., 2019). The AKP activity of whole FB group was the highest among the six groups both on $50 \mathrm{~d}$ and $100 \mathrm{~d}(P<0.05)$ (Fig. 3C). The whole FB group showed the higher value of GPT activity (Fig. 3E), but GOT and POD activities of whole FB group were lower than those of the control on $100 \mathrm{~d}$ (Fig. 3D and F).

\section{Hepatopancreatic oxidative abilities}

Changes in the oxidative parameters of SOD, NADPH, NADP ${ }^{+}, \mathrm{H}_{2} \mathrm{O}_{2}, \mathrm{~T}-\mathrm{GSH}$, and GSSH were measured in the hepatopancreas (Fig. 4). On $100 \mathrm{~d}$, the SOD activity, NADPH content, and $\mathrm{H}_{2} \mathrm{O}_{2}$ content of the FB and four FB extract groups were lower than those of the control group $(P<$ 
217 0.05) except for the $\mathrm{H}_{2} \mathrm{O}_{2}$ content of the FB water extract group (Fig. 4A, B and D). The T-GSH

218 and GSSH contents of the FB, FB alcohol extract and FB residues groups were higher than those 219 of the control group on $100 \mathrm{~d}(P<0.05)$ (Fig. 4E and F). The NADP ${ }^{+}$content of the FB, FB

220 proteins and FB residues groups were higher than that of the control group on $100 \mathrm{~d}(P<0.05)$

221 (Fig. 4C).

222

223

224

225

226

227

228

229

230

231

232

233

234

235

236

237

238

239

240

241

242

243

244

245

246

247

248

249

250

251

252

253

254

255

\section{Histological structure of hepatopancreas}

The hepatopancreas microstructures of the six groups were observed on $100 \mathrm{~d}$ (Fig. 5). Most lipid vacuoles (LV) were found in the FB and FB alcohol extract groups (Fig. 5B and C), followed by the FB water extract and FB proteins groups. Compared with the control group, the number of nuclei $(\mathrm{N})$ were reduced in the FB water extract and FB proteins groups (Fig. 5A, D and $\mathrm{E}$ ). In addition, minor cellular infiltration was found in the FB proteins and FB residues groups (Fig. 5E and F).

\section{DISCUSSION}

Hematological analysis is an important tool in evaluating the physiological status of fish since hematological parameters are affected by a multitude of intrinsic and extrinsic factors, such as feed, health condition, oxygen, etc. (Clauss et al., 2008; Fazio, 2018). It has been reported that ingestion of faba bean leads to hemolysis, which results in reduced red blood cell count (RBC) and decreased hemoglobin content, and thereby increases the oxygen requirement in grass carp (Yu et al., 2017). Our previous study has found that the FB and FB water extract groups have low RBC and glucose-6-phosphate dehydrogenase (G6PD) activity, which possibly causes hemolysis (Ma et al., 2020). In this study, we conducted a more detailed hematological analysis. The results showed evidence of oxidative damage to red blood cells, but the FB water extract group displayed improved count and morphology compared to the whole FB group on $50 \mathrm{~d}$. These results suggest that the acute damage caused by FB could be alleviated in the FB water extract group compared to the whole FB group. White blood cell parameters, on the other hand, are generally associated with pathological conditions of fish. Because our experimental fish appeared healthy throughout the feeding trial, it is not surprising that we observed no clear tendencies in white blood cell parameters. Only the group fed with the FB residues feed, which appears to be the most detrimental, showed a marked increase in neutrophils.

Lipid metabolism is related to fish nutrition and health, and the dysfunction of lipid metabolism (dyslipidemia) often leads to fat accumulation, which mainly results in high total cholesterol (TC) and high triglycerides (TG) contents (Howard et al., 2003). Previous studies have shown that fat accumulation increases in grass carp that are fed faba bean (Tian et al., 2019; Wang et al., 2015). The results of the present study further suggest that the causative compound(s) of hepatopancreatic fat accumulation is/are alcohol-soluble for the following reasons. First, high TC and TG contents were observed in the hepatopancreas of both the FB and FB alcohol extract groups. Second, lipid vacuoles were increased with the concomitant decrease 
257

in the number of hepatopancreatic cell nuclei in the FB and FB alcohol extract groups. Alcohol extract from clove basil leaf also contains an unidentified substance(s) that affects fish lipid metabolism (Abdel-Tawwab et al., 2018), although its effect is opposite (i.e., reduces fat accumulation), reflecting the diversity of plant-derived substances.

In fish, alkaline phosphatase (AKP), glutamic oxalacetic transaminase (GOT) and glutamicpyruvic transaminase (GPT) are key enzymes in amino acid metabolism and have been used as important indices to evaluate hepatopancreatic conditions (Wu et al., 2017). Higher activities of these enzymes in the hepatopancreas generally imply that fish are under stressful conditions (Wang et al., 2014). These are also deviation enzymes released into plasma upon hepatopancreas damage and dysfunction (Li et al., 2017; Tan et al., 2017). The activities of these enzymes in the hepatopancreas fluctuated in the present study but were generally comparable to those of the control group. The serum activities of AKP, GOT, and GPT were sometimes higher than those of the control group, suggesting the hepatopancreatic damage. Combined with the hepatopancreas histology, it is speculated that the FB water extract induced minimal hepatopancreas damage, the FB alcohol extract induced mild hepatopancreas damage, and the whole FB caused the most serious hepatopancreas damage.

Furthermore, oxidative parameters indicated that $\mathrm{FB}$ residues induced hepatopancreas damage more than other extracts. The NADP ${ }^{+}, \mathrm{T}-\mathrm{GSH}$ and GSSH contents of the FB and FB residues groups were higher than those of the control group. The histology of the FB residues group also showed serious hepatopancreas damage. NADPH plays an important role in protecting cells from oxidative stress, since it affects the content of glutathione (T-GSH, GSSH), which reduces the level of $\mathrm{H}_{2} \mathrm{O}_{2}$ (Boonyuen et al., 2017; Cappellini \& Fiorelli, 2008). It has been found that faba bean cause hepatopancreas damage and reduce non-specific immune response of tilapia (Chen, 2015), but it is unclear which component of the faba bean causes the damage. Further studies on FB residues will help the identification of the oxidative compounds in faba bean, possibly facilitating the effective removal of the oxidative substances.

A limitation of this study is that the experimental time lasted for $100 \mathrm{~d}$ through fall and winter. Although the water temperature was kept relatively constant $\left(25-30^{\circ} \mathrm{C}\right)$, the activities of metabolic enzymes are influenced by water temperature and seasonal variation (Qiang et al., 2014; Jobling, 2016; Richard et al., 2016). Our experimental conditions should have practical implications for the application of faba bean in aquaculture, but this may explain why some enzyme activities and tissue weights were not consistent between $50 \mathrm{~d}$ and $100 \mathrm{~d}$. In this regard, liver histology may provide more robust information about hepatopancreatic damages rather than enzymatic activities during the experimental period. Another limitation is that the diets were not isoenergetic or isonitrogenous, which may be related to the inconsistency between nutrition and health status. In particular, the four FB extracts differed in proteins content, which affects fish physiology to a great extent. Although our main finding was based on the comparison between the FB water extract and commercial feed that have similar protein content, feed formulation requires improvements to gain mechanical insights. In the near future, we will further examine 
296

297

298

299

300

301

302

303

304

305

306

307

308

309

310

311

312

313

314

315

316

317

318

319

320

321

322

323

324

325

326

327

328

329

330

331

332

333

334

335

336

337

338

the effects of these four FB extracts by formulating isoenergetic and isonitrogenous diets containing faba bean extracts.

\section{CONCLUSION}

In the present study, the FB water extract group had a better health status than FB and other extract groups in terms of rapid growth, normal lipid metabolism, and minimal hepatopancreas damage. The FB alcohol extract and proteins groups had an inferior health status compared with the FB water extract group, with the FB and FB residues groups ranking last. Therefore, this study successfully separated the beneficial and detrimental substances of faba bean. Given that the FB water extract by itself can improve the textural quality (Ma et al., 2020), this could become a promising food additive in grass carp culture. In the near future, we will further analyze the beneficial and detrimental effects of these four FB extracts by formulating isoenergetic and isonitrogenous diets, and carry out a detailed evaluation based on intestinal microbes and metabolites, etc.

\section{DECLARATION OF COMPETEING INTEREST}

The authors declare that they have no known competing financial interests or personal relationships that could have appeared to influence the work reported in this paper.

\section{ACKNOWLEDGEMENTS}

This study was funded by the Modern Agro-industry Technology Research System (No.CARS45-21).

\section{REFERENCES}

Abdel-Tawwab M, Adeshina I, Jenyo-Oni A, Ajani EK, Emikpe BO. 2018. Growth, physiological, antioxidants, and immune response of African catfish, Clarias gariepinus (B.), to dietary clove basil, Ocimum gratissimum, leaf extract and its susceptibility to Listeria monocytogenes infection. Fish \& Shellfish Immunology 78:346-354 DOI 10.1016/j.fsi.2018.04.057.

Boonyuen U, Chamchoy K, Swangsri T, Junkree T, Day NP, White NJ, Imwong M. 2017. A trade off between catalytic activity and protein stability determines the clinical manifestations of glucose-6-phosphate dehydrogenase (G6PD) deficiency. International Journal of Biological Macromolecules 104:145-156 DOI 10.1016/j.ijbiomac.2017.06.002.

Cappellini MD, Fiorelli G. 2008. Glucose-6-phosphate dehydrogenase deficiency. Journal of Pediatrics 371:64-74 DOI 10.1016/S0140-6736(08)60073-2.

Clauss TM, Dove AD, Arnold JE. 2008. Hematologic disorders of fish. Veterinary Clinics North America: Exotic Animal Practice 11:445-462 DOI 10.1016/j.cvex.2008.03.007

Chen DH. 2015. Effects of feeding broad bean on liver injury and non-specific immune responses of tilapia. China Feed 13:24-26 DOI 10.15906/j.cnki.cn11-2975/s.20151307.

Chen LJ, Yu EM, Wang GJ, Xun J, Yu DG, Li ZF, Zhang K, Gong WB. 2019. Effects of feeding broad bean on ultrastructure and immune gene expression of immune organs of grass carp. 
Journal of China Agricultural University 24(6):92-103 DOI 10.11841/j.issn.10074333.2019.06.11.

De Santis C, Secombes CJ, Tocher DR, Ruohonen K, El-Mowafi A, Martin SAM, Dehler CE, Crampton V. 2016. Air-classified faba bean protein concentrate is efficiently utilized as a dietary protein source by post-smolt Atlantic salmon (Salmo salar). Aquaculture 452:169-177 DOI 10.1016/j.aquaculture.2015.10.035.

Fazio FJA. 2018. Fish hematology analysis as an important tool of aquaculture: A review. Aquaculture 500:237-242 DOI 10.1016/j.aquaculture.2018.10.030.

Fu B, Yu EM, Wang GJ, Xie J, Li LF, Zhang K, Gong WB, Tian JJ. 2020. Effects of feeding broad bean on fat accumulation and fat metabolism in grass carp liver. Journal of Shanghai Ocean University 29(01):45-54 DOI 10.12024/jsou.20190302546.

Gan L, Li XX, Pan Q, Wu SL, Feng T, Ye H. 2017. Effects of replacing soybean meal with faba bean meal on growth, feed utilization and antioxidant status of juvenile grass carp, Ctenopharyngodon idella. Aquaculture Nutrition 23:192-200 DOI 10.1111/anu.12380.

Howard BV, Ruotolo G, Robbins DC. 2003. Obesity and dyslipidemia. Endocrinology and Metabolism Clinics of North America 32:855-867. DOI 10.1016/s0889-8529(03)00073-2

Jobling M. 2016. Fish nutrition research: past, present and future. Aquaculture International 24(3): 767786 DOI 10.1007/s10499-014-9875-2.

Li S, Ji H, Zhang B, Zhou J, Yu HB. 2017. Defatted black soldier fly (Hermetia illucens) larvae meal in diets for juvenile Jian carp (Cyprinus carpio var. Jian): Growth performance, antioxidant enzyme activities, digestive enzyme activities, intestine and hepatopancreas histological structure. Aquaculture 477:62-70 DOI 10.1016/j.aquaculture.2017.04.015.

Li Z, Yu E, Wang G, Yu D, Zhang K, Wang W, Xie J. 2018. Broad Bean (Vicia faba L.) Induces Intestinal Inflammation in Grass Carp (Ctenopharyngodon idellus C. et V) by Increasing Relative Abundances of Intestinal Gram-negative and Flagellated Bacteria. Frontiers in Microbiology 9:1913 DOI 10.3389/fmicb.2018.01913.

Lin WL, Zeng QX, Zhu ZW. 2009. Different changes in mastication between crisp grass carp (Ctenopharyngodon idellus $\mathrm{C}$. et $\mathrm{V}$ ) and grass carp (Ctenopharyngodon idellus) after heating: the relationship between texture and ultrastructure in muscle tissue. Food Research International 42:271-278 DOI 10.1016/j.foodres.2008.11.005.

Ma LL, Kaneko G, Wang XJ, Xie J, Tian JJ, Zhang K, Wang GJ, Yu DG, Li ZF, Gong WB. 2020. Effects of four faba bean extracts on growth parameters, textural quality, oxidative responses, and gut characteristics in grass carp. Aquaculture 516:734620 DOI 10.1016/j.aquaculture.2019.734620.

Macarulla MT, Medina C, De Diego MA, Chavarri M, Zulet MÁ, Martínez JA, NoÈel-Suberville C, Higueret P, Portillo MP. 2001. Effects of the whole seed and a protein isolate of faba bean (Vicia faba) on the cholesterol metabolism of hypercholesterolaemic rats. British Journal of Nutrition 85:607-614 DOI 10.1079/BJN2000330.

Multari S, Stewart D, Russell WR. 2015. Potential of fava bean as future protein supply to partially replace meat intake in the human diet. Comprehensive Reviews in Food Science and Food Safety 14:511-522 DOI 10.1111/1541-4337.12146.

Qiang J, He J, Yang H, Wang H, Kpundeh MD, Xu P. 2014. Temperature modulates hepatic carbohydrate metabolic enzyme activity and gene expression in juvenile gift tilapia (Oreochromis niloticus) fed a carbohydrate-enriched diet. Journal of Thermal Biology 40: 25-31 DOI 10.1016/j.jtherbio.2013.12.003.

Richard N, Silva TS, Wulff T, Schrama D, Dias JP, Rodrigues PM, Conceição LE. 2016. Nutritional mitigation of winter thermal stress in gilthead seabream: associated metabolic pathways and potential indicators of nutritional state. Journal of Proteomics 142: 1-14 DOI 10.1016/j.jprot.2016.04.037.

Soltanzadeh S, Fereidouni AE, Ouraji H, Khalili KJ. 2016. Growth performance, body composition, hematological, and serum biochemical responses of beluga (Huso huso) juveniles to different 
dietary inclusion levels of faba bean (Vicia faba) meal. Aquaculture International 24:395-413 DOI 10.1007/s10499-015-9933-4.

Tan X, Sun Z, Chen S, Chen S, Huang Z, Zhou C, Zou C, Liu Q, Ye H, Lin ZH. 2017. Effects of dietary dandelion extracts on growth performance, body composition, plasma biochemical parameters, immune responses and disease resistance of juvenile golden pompano Trachinotus ovatus. Fish \& Shellfish Immunology 66:198-206 DOI 10.1016/j.fsi.2017.05.028.

Tan Q, Li SH. 2005. Preliminary study on the ecology, physiology and pathology of crisped grass carp (Ctenopharyngodon idellus C.et V). Acta Ecologica Sinica 26:2749-2756 DOI 10.3321/j.issn:1000-0933.2006.08.044.

Tian JJ, Ji H, Wang YF, Xie J, Wang GJ, Li ZF, Yu EM, Yu DG, Zhang K, Gong WB. 2019. Lipid accumulation in grass carp (Ctenopharyngodon idellus) fed faba beans (Vicia faba L.). Fish Physiology and Biochemistry 45:631-642 DOI 10.1007/s10695-018-0589-7.

Wang LN, Liu WB, Lu KL, Xu WN, Cai DS, Zhang CN, Qian YJA. 2014. Effects of dietary carbohydrate/lipid ratios on non-specific immune responses, oxidative status and liver histology of juvenile yellow catfish Pelteobagrus fulvidraco. Aquaculture 426:41-48 DOI 10.1016/j.aquaculture.2014.01.022.

Wang YF, Ji H, Chen HJ, Yu EM, Xie J. 2015. Effects of feeding broad bean on muscle texture characteristics,lipid accumulation and tissue fatty acid composition of grass carp (Ctenopharynodon idellus). Journal of Southern Agriculture 46(11):2040-2045 DOI 10.3969/j:issn.2095-1191.2015.11.2040.

Wu CL, Chen L, Lu ZB, Gao J, Chu YD, Li L, Wang M, Zhang GY, Zhang MT, Ye JY. 2017. The effects of dietary leucine on the growth performances, body composition, metabolic abilities and innate immune responses in black carp Mylopharyngodon piceus. Fish \& shellfish immunology 67: 419-428 DOI 10.1016/j.fsi.2017.06.033.

Xu WH, Guo HH, Chen SJ, Wang YZ, Lin ZH, Huang XD, Tang HJ, He YH, Sun JJ, Gan, L. 2020. Transcriptome analysis revealed changes of multiple genes involved in muscle hardness in grass carp (Ctenopharyngodon idellus) fed with faba bean meal. Food Chemistry 341:126205 DOI 10.1016/j.foodchem.2020.126205.

Yu E, Fu B, Wang G, Li Z, Ye D, Jiang Y, Ji H, Wang X, Yu D, Ehsan H, Gong W, Zhang K, Tian J, Yu L, Hu Z, Xie J, Kaneko G. 2020. Proteomic and metabolomic basis for improved textural quality in crisp grass carp (Ctenopharyngodon idellus $\mathrm{C}$. et $\mathrm{V}$ ) fed with a natural dietary prooxidant. Food Chemistry 325:126906. DOI 10.1016/j.foodchem.2020.126906.

Yu EM, Zhang HF, Li ZF, Wang GJ, Wu HK, Xie J, Yu DG, Xia Y, Zhang K, Gong WB. 2017. Proteomic signature of muscle fibre hyperplasia in response to faba bean intake in grass carp. Scientific Reports 7:45950 DOI 10.1038/srep45950.

Zhang ZN, Yu EM, Xie J, Wang GJ, Yu DG, Li ZF, Gong WB, Wang HY, Wei N, Xia Y. 2015. Intestinal microflora dynamic change, serum enzyme and growth performance of the grass carp (Ctenopharyngodon idellus) at different stages of feeding broad bean (Vicia faba). Journal of Agricultural Biotechnology 23:151-160 DOI 10.3969/j.issn.1674-7968.2015.02.002. 


\section{Table 1 (on next page)}

Nutritive components of four faba bean extracts and six diets 


\section{Table 1}

2 Nutritive components of four faba bean extracts and six diets

\begin{tabular}{lcccc}
\hline & $\begin{array}{c}\text { Crude Protein } \\
(\mathrm{g} / 100 \mathrm{~g})\end{array}$ & $\begin{array}{c}\text { Crude Fat } \\
(\mathrm{g} / 100 \mathrm{~g})\end{array}$ & $\begin{array}{c}\text { Moisture } \\
(\mathrm{g} / 100 \mathrm{~g})\end{array}$ & $\begin{array}{c}\text { Crude Ash } \\
(\mathrm{g} / 100 \mathrm{~g})\end{array}$ \\
\hline FBA & 36.8 & 10.5 & 10.4 & $<0.1$ \\
FBW & 37.4 & $<0.5$ & 10.2 & 3.9 \\
FBP & 58.6 & 2.8 & 10.1 & 3.9 \\
FBR & 6.6 & 0.65 & 12.2 & 7.7 \\
\hline Control & 28.8 & 5.5 & 10.9 & 8.1 \\
diet & 28 & 1.4 & 14.4 & 4.1 \\
FB diet & 36.8 & 10.5 & 10.4 & 8.5 \\
FBA diet & 29.85 & 4.87 & 10.81 & 7.75 \\
FBW diet & 37.71 & 4.69 & 10.66 & 6.84 \\
FBP diet & 71.72 & 3.08 & 11.55 & 7.9 \\
FBR diet & & & & \\
\hline
\end{tabular}

3 Note: Control, commercial feed; FB, whole faba bean; FBA, FB alcohol extract; FBW, FB water

4 extract; FBP, FB proteins; FBR, FB residues.

5

6

7

8

9

10

11

12

13 


\section{Table 2 (on next page)}

Effect of faba bean and four extracts on growth parameters of grass carp on $50 \mathrm{~d}$ and $100 \mathrm{~d}$ 


\section{$1 \quad$ Table 2}

2 Effect of faba bean and four extracts on growth parameters of grass carp on $50 \mathrm{~d}$ and $100 \mathrm{~d}$

\begin{tabular}{|c|c|c|c|c|c|c|}
\hline Days & Groups & $\begin{array}{c}\text { Weight gain rate } \\
(\%)\end{array}$ & $\begin{array}{c}\text { Condition factor } \\
(\%)\end{array}$ & $\begin{array}{l}\text { Visceral somatic } \\
\text { index }(\%)\end{array}$ & $\begin{array}{c}\text { Hepatopancreas } \\
\text { somatic index (\%) }\end{array}$ & $\begin{array}{c}\text { Abdominal fat } \\
\text { index }(\%)\end{array}$ \\
\hline \multirow{6}{*}{$50 \mathrm{~d}$} & Control & $27.42 \pm 1.37^{\mathrm{bc}}$ & $20.72 \pm 0.67^{\mathrm{ab}}$ & $11.13 \pm 0.67^{\mathrm{ab}}$ & $1.97 \pm 0.08^{\mathrm{a}}$ & $1.68 \pm 0.38^{\mathrm{ab}}$ \\
\hline & FB & $14.24 \pm 0.48^{\mathrm{d}}$ & $21.26 \pm 2.04^{\mathrm{ab}}$ & $11.05 \pm 1.09^{\mathrm{ab}}$ & $1.48 \pm 0.10^{\mathrm{a}}$ & $2.01 \pm 0.39^{\mathrm{a}}$ \\
\hline & FBA & $18.7 \pm 0.60^{\mathrm{cd}}$ & $20.90 \pm 1.38^{\mathrm{ab}}$ & $9.37 \pm 0.51^{b}$ & $1.96 \pm 0.23^{\mathrm{a}}$ & $1.14 \pm 0.22^{\mathrm{ab}}$ \\
\hline & FBW & $43.34 \pm 3.55^{\mathrm{a}}$ & $24.34 \pm 1.59^{\mathrm{a}}$ & $14.86 \pm 3.02^{\mathrm{a}}$ & $1.93 \pm 0.17^{\mathrm{a}}$ & $1.26 \pm 0.22^{\mathrm{ab}}$ \\
\hline & FBP & $33.11 \pm 2.96^{\mathrm{b}}$ & $22.73 \pm 0.70^{\mathrm{ab}}$ & $9.09 \pm 0.77^{b}$ & $1.83 \pm 0.28^{\mathrm{a}}$ & $1.55 \pm 0.31^{\mathrm{ab}}$ \\
\hline & FBR & $2.96 \pm 0.41^{\mathrm{e}}$ & $18.38 \pm 1.78^{b}$ & $4.62 \pm 0.61^{\mathrm{c}}$ & $0.64 \pm 0.14^{\mathrm{b}}$ & $0.84 \pm 0.08^{\mathrm{b}}$ \\
\hline \multirow{6}{*}{$100 \mathrm{~d}$} & Control & $34.48 \pm 2.18^{b}$ & $35.58 \pm 4.16^{\mathrm{a}}$ & $12.93 \pm 0.28^{\mathrm{a}}$ & $3.23 \pm 0.25^{\mathrm{a}}$ & $2.62 \pm 0.05^{\mathrm{a}}$ \\
\hline & FB & $8.19 \pm 0.39^{\mathrm{d}}$ & $27.16 \pm 0.59^{b}$ & $13.07 \pm 1.91^{\mathrm{a}}$ & $1.83 \pm 0.18^{\mathrm{c}}$ & $3.66 \pm 0.63^{\mathrm{a}}$ \\
\hline & FBA & $47.33 \pm 3.29^{\mathrm{a}}$ & $40.80 \pm 3.08^{\mathrm{a}}$ & $13.92 \pm 0.32^{\mathrm{a}}$ & $3.08 \pm 0.19^{\mathrm{ab}}$ & $3.24 \pm 0.68^{\mathrm{a}}$ \\
\hline & FBW & $40.12 \pm 1.72^{\mathrm{ab}}$ & $39.27 \pm 2.27^{\mathrm{a}}$ & $12.53 \pm 1.36^{\mathrm{a}}$ & $3.14 \pm 0.36^{\mathrm{ab}}$ & $3.17 \pm 0.65^{\mathrm{a}}$ \\
\hline & FBP & $38.27 \pm 0.09^{b}$ & $35.01 \pm 1.03^{\mathrm{a}}$ & $11.90 \pm 0.53^{\mathrm{a}}$ & $2.31 \pm 0.34^{\mathrm{bc}}$ & $3.87 \pm 0.53^{\mathrm{a}}$ \\
\hline & FBR & $10.91 \pm 1.05^{\mathrm{d}}$ & $27.46 \pm 0.68^{b}$ & $10.50 \pm 0.86^{\mathrm{a}}$ & $2.53 \pm 0.13^{\mathrm{abc}}$ & $2.37 \pm 0.30^{\mathrm{a}}$ \\
\hline
\end{tabular}

3

4 Note: Control, commercial feed; FB, whole faba bean; FBA, FB alcohol extract; FBW, FB water 5 extract; FBP, FB proteins; FBR, FB residues. 


\section{Table 3 (on next page)}

Effect of the faba bean and four faba bean extracts on hematological parameters of grass carp on $50 \mathrm{~d}$ and $100 \mathrm{~d}$ 


\section{Table 3}

2 Effect of the faba bean and four faba bean extracts on hematological parameters of grass carp on $50 \mathrm{~d}$ and $100 \mathrm{~d}$

\begin{tabular}{|c|c|c|c|c|c|c|c|c|c|c|}
\hline \multirow[b]{2}{*}{ Groups } & \multicolumn{6}{|c|}{$50 \mathrm{~d}$} & \multirow[b]{2}{*}{ Control } & \multicolumn{3}{|c|}{$100 \mathrm{~d}$} \\
\hline & Control & FB & FBA & FBW & FBP & $\overline{F B R}$ & & FB & FBA & $\overline{F I}$ \\
\hline $\mathrm{RBC}\left(10^{12} / \mathrm{L}\right)$ & $2.64 \pm 0.38^{\mathrm{a}}$ & $1.98 \pm 0.45^{\mathrm{bc}}$ & $2.34 \pm 0.16^{\mathrm{ab}}$ & $2.58 \pm 0.25^{\mathrm{a}}$ & $2.54 \pm 0.20^{\mathrm{a}}$ & $1.73 \pm 0.14^{\mathrm{c}}$ & $2.37 \pm 0.29^{\mathrm{ab}}$ & $2.15 \pm 0.10^{\mathrm{bc}}$ & $2.47 \pm 0.04^{\mathrm{a}}$ & \\
\hline $\operatorname{HCT}(\%)$ & $37.63 \pm 6.54^{\mathrm{ab}}$ & $29.37 \pm 1.02^{\mathrm{bc}}$ & $36.00 \pm 4.27^{\mathrm{abc}}$ & $37.43 \pm 3.35^{\mathrm{ab}}$ & $46.83 \pm 13.06^{\mathrm{a}}$ & $24.70 \pm 2.78^{c}$ & $32.40 \pm 4.09^{\mathrm{ab}}$ & $29.23 \pm 1.43^{\mathrm{b}}$ & $43.23 \pm 15.17^{\mathrm{a}}$ & $28.80=$ \\
\hline $\mathrm{MCV}(\mathrm{fL})$ & $142.13 \pm 4.85^{\mathrm{a}}$ & $155.20 \pm 44.38^{\mathrm{a}}$ & $155.37 \pm 29.73^{\mathrm{a}}$ & $145.53 \pm 6.16^{\mathrm{a}}$ & $182.97 \pm 41.90^{\mathrm{a}}$ & $142.30 \pm 4.59^{\mathrm{a}}$ & $136.90 \pm 3.72^{\mathrm{a}}$ & $135.97 \pm 7.21^{\mathrm{a}}$ & $175.47 \pm 63.23^{\mathrm{a}}$ & $143.6^{\prime}$ \\
\hline $\operatorname{HGB}(\mathrm{g} / \mathrm{L})$ & $123.67 \pm 19.63^{\mathrm{a}}$ & $92.33 \pm 16.26^{b c}$ & $107.33 \pm 10.69^{\mathrm{ab}}$ & $118.67 \pm 15.95^{\mathrm{a}}$ & $120.00 \pm 11.14^{\mathrm{a}}$ & $77.00 \pm 7.00^{c}$ & $108.00 \pm 14.53^{\mathrm{ab}}$ & $97.00 \pm 5.57^{b}$ & $116.33 \pm 5.51^{\mathrm{a}}$ & $93.00=$ \\
\hline $\mathrm{MCH}(\mathrm{pg})$ & $46.73 \pm 0.91^{\mathrm{a}}$ & $47.07 \pm 3.59^{\mathrm{a}}$ & $45.80 \pm 1.65^{\mathrm{a}}$ & $46.10 \pm 2.46^{\mathrm{a}}$ & $47.17 \pm 2.01^{\mathrm{a}}$ & $44.27 \pm 0.70^{\mathrm{a}}$ & $45.60 \pm 0.87^{\mathrm{a}}$ & $45.13 \pm 0.49^{\mathrm{a}}$ & $47.20 \pm 2.46^{\mathrm{a}}$ & $46.33=$ \\
\hline $\mathrm{WBC}\left(10^{9} / \mathrm{L}\right)$ & $17.76 \pm 7.17^{\mathrm{a}}$ & $8.82 \pm 4.40^{\mathrm{b}}$ & $12.53 \pm 2.45^{\mathrm{ab}}$ & $13.58 \pm 2.67^{\mathrm{ab}}$ & $12.86 \pm 0.53^{\mathrm{ab}}$ & $11.05 \pm 3.25 \mathrm{a}^{\mathrm{b}}$ & $16.85 \pm 2.90^{\mathrm{a}}$ & $11.34 \pm 1.94^{\mathrm{a}}$ & $15.67 \pm 5.06^{\mathrm{a}}$ & 17.7 \\
\hline NEU\# $\left(10^{9} / \mathrm{L}\right)$ & $5.94 \pm 5.24^{\mathrm{a}}$ & $0.49 \pm 0.75^{b}$ & $0.22 \pm 0.11^{\mathrm{b}}$ & $0.12 \pm 0.09^{\mathrm{b}}$ & $0.15 \pm 0.10^{\mathrm{b}}$ & $0.08 \pm 0.07^{\mathrm{b}}$ & $0.90 \pm 0.61^{\mathrm{b}}$ & $0.78 \pm 0.64^{b}$ & $1.32 \pm 0.55^{\mathrm{b}}$ & 2.25 \\
\hline NEU\% & $28.27 \pm 22.33^{\mathrm{a}}$ & $5.30 \pm 7.72^{b}$ & $1.90 \pm 1.15^{\mathrm{b}}$ & $0.87 \pm 0.57^{b}$ & $1.13 \pm 0.75^{b}$ & $0.63 \pm 0.38^{b}$ & $5.03 \pm 2.83^{b}$ & $7.67 \pm 7.66^{b}$ & $8.90 \pm 4.62^{b}$ & 12.17 \\
\hline $\operatorname{LY}\left(10^{9} / \mathrm{L}\right)$ & $10.84 \pm 1.25^{\mathrm{a}}$ & $8.02 \pm 4.30^{\mathrm{a}}$ & $11.81 \pm 3.02^{\mathrm{a}}$ & $13.07 \pm 2.49^{\mathrm{a}}$ & $12.40 \pm 0.73^{\mathrm{a}}$ & $10.25 \pm 2.96^{\mathrm{a}}$ & $15.63 \pm 2.05^{\mathrm{a}}$ & $9.97 \pm 2.70^{\mathrm{ab}}$ & $13.77 \pm 4.58^{\mathrm{ab}}$ & 14.88 \\
\hline LY\% & $67.23 \pm 24.85^{\mathrm{b}}$ & $90.40 \pm 6.74^{\mathrm{a}}$ & $93.57 \pm 5.82^{\mathrm{a}}$ & $96.33 \pm 2.02^{\mathrm{a}}$ & $96.40 \pm 2.17^{\mathrm{a}}$ & $92.87 \pm 1.66^{\mathrm{a}}$ & $93.23 \pm 4.31^{\mathrm{a}}$ & $86.83 \pm 10.34^{\mathrm{a}}$ & $87.63 \pm 5.26^{\mathrm{a}}$ & $84.20=$ \\
\hline $\operatorname{EOS} \#\left(10^{9} / \mathrm{L}\right)$ & $0.98 \pm 1.14^{\mathrm{a}}$ & $0.32 \pm 0.08^{\mathrm{a}}$ & $0.50 \pm 0.49^{\mathrm{a}}$ & $0.39 \pm 0.34^{\mathrm{a}}$ & $0.31 \pm 0.32^{\mathrm{a}}$ & $0.72 \pm 0.26^{\mathrm{a}}$ & $0.33 \pm 0.31^{\mathrm{a}}$ & $0.59 \pm 0.32^{\mathrm{a}}$ & $0.58 \pm 0.39^{\mathrm{a}}$ & 0.62 \\
\hline $\operatorname{PLT}\left(10^{9} / \mathrm{L}\right)$ & $12.67 \pm 5.03^{\mathrm{bc}}$ & $24.00 \pm 11.00^{\mathrm{ab}}$ & $19.00 \pm 6.00^{\mathrm{abc}}$ & $7.33 \pm 5.57^{\mathrm{c}}$ & $13.00 \pm 5.57^{\mathrm{bc}}$ & $29.00 \pm 13.75^{\mathrm{a}}$ & $25.00 \pm 12.17^{\mathrm{ab}}$ & $14.00 \pm 4.36^{\mathrm{b}}$ & $27.33 \pm 4.62^{\mathrm{a}}$ & 25.3 \\
\hline PDW(\%) & $17.50 \pm 1.27^{\mathrm{ab}}$ & $18.67 \pm 0.35^{\mathrm{ab}}$ & $18.40 \pm 1.01^{\mathrm{ab}}$ & $17.00 \pm 1.04^{b}$ & $18.27 \pm 0.78^{\mathrm{ab}}$ & $19.00 \pm 0.35^{\mathrm{a}}$ & $17.87 \pm 0.59^{\mathrm{ab}}$ & $17.83 \pm 0.55^{\mathrm{b}}$ & $18.57 \pm 0.45^{\mathrm{ab}}$ & $18.17=$ \\
\hline MPV( fL) & $7.97 \pm 1.00^{\mathrm{ab}}$ & $8.97 \pm 0.45^{\mathrm{ab}}$ & $8.60 \pm 0.78^{\mathrm{ab}}$ & $7.70 \pm 0.98^{\mathrm{b}}$ & $7.90 \pm 0.30^{\mathrm{ab}}$ & $9.47 \pm 1.12^{\mathrm{a}}$ & $8.43 \pm 0.99^{\mathrm{a}}$ & $8.23 \pm 1.00^{\mathrm{a}}$ & $8.73 \pm 0.58^{\mathrm{a}}$ & 8.63 \\
\hline $\operatorname{PCT}(\%)$ & $0.01 \pm 0.00^{\mathrm{bc}}$ & $0.02 \pm 0.01^{\mathrm{ab}}$ & $0.02 \pm 0.00^{\mathrm{abc}}$ & $0.01 \pm 0.00^{\mathrm{c}}$ & $0.01 \pm 0.00 \mathrm{~b}^{\mathrm{c}}$ & $0.03 \pm 0.01^{\mathrm{a}}$ & $0.02 \pm 0.01^{\mathrm{ab}}$ & $0.01 \pm 0.00^{\mathrm{b}}$ & $0.02 \pm 0.01^{\mathrm{a}}$ & 0.02 \\
\hline
\end{tabular}

3

4 Note: Control, commercial feed; FB, whole faba beans; FBA, FB alcohol extract; FBW, FB water extract; FBP, FB proteins; FBR, FB

5 residues.

6 RBC (1012/L), red blood cell count; HCT(\%), hematocrit; MCV(fL), mean corpuscular volume; HGB(g/L), hemoglobin; MCH (pg),

7 mean erythrocyte hemoglobin contents; WBC (10\%/L), white blood cell count; NEU\#, number of neutrophils; NEU\%, percentage of

8 neutrophils; LY(10\%/L), lymphocyte count; EOS\# (109/L), eosinophil number; PLT(109/L), Platelet count; PDW(\%), platelet

9 distribution width; MVP(fL), mean platelet volume; PCT(\%), plateletocrit. 


\section{Figure 1}

Fig. 1 Serum lipid metabolism parameters of grass carp on $50 \mathrm{~d}$ and $100 \mathrm{~d}$

Control, commercial feed; FB, whole faba bean; FBA, FB alcohol extract; FBW, FB water

extract; FBP, FB proteins; FBR, FB residues . A, total cholesterol (TC); B, triglycerides (TG); C

high density lipoprotein cholesterol (HDL-C); D, low density lipoprotein cholesterol (LDL-C).

Different letters are significantly different $(P<0.05)$.

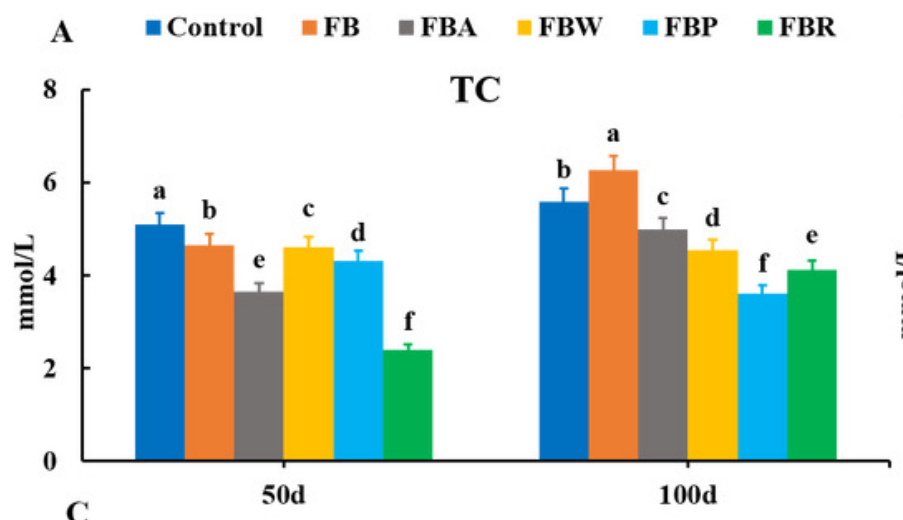

B
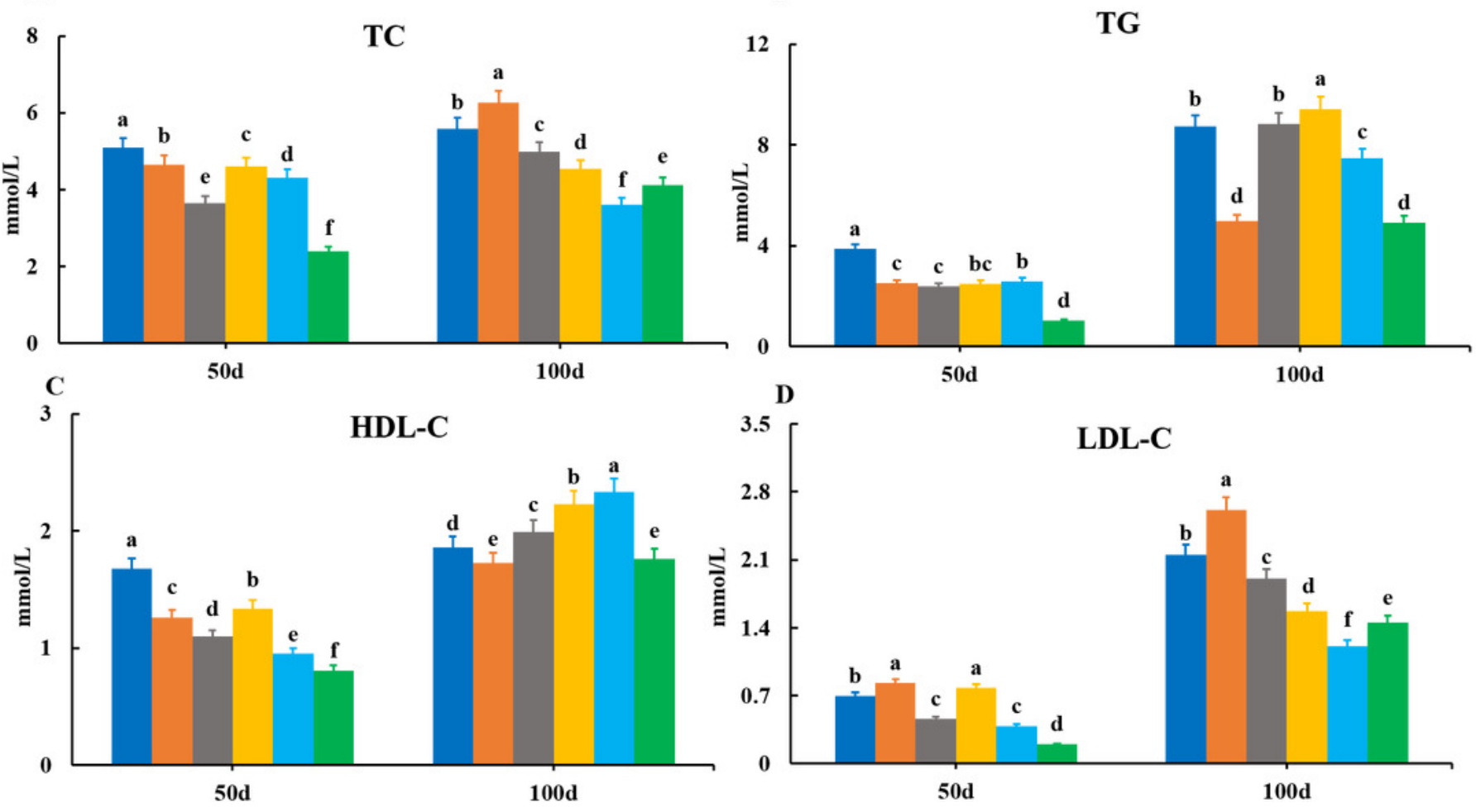

LDL-C 
Figure 2

Fig. 2 Serum enzymatic parameters of grass carp on $50 d$ and $100 d$

Control, commercial feed; FB, whole faba bean; FBA, FB alcohol extract; FBW, FB water extract; FBP, FB proteins; FBR, FB residues. A, glutamic-pyruvic transaminase (GPT); B, glutamic oxalacetic transaminase (GOT); C, alkaline phosphatase (AKP); D, peroxidase (POD). Different letters are significantly different $(P<0.05)$.
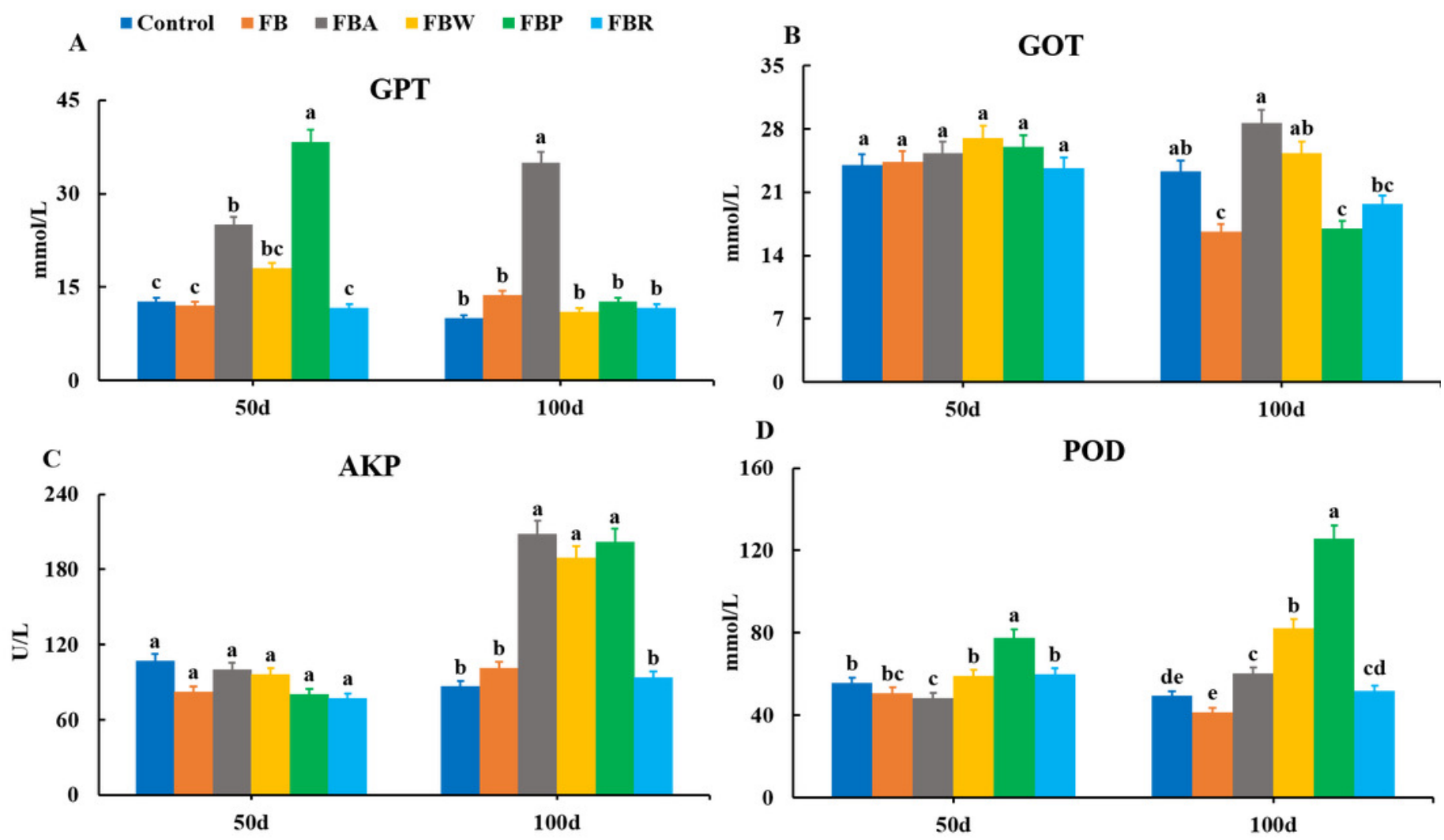


\section{Figure 3}

Fig. 3 Hepatopancreatic lipid metabolic parameters of grass carp on $50 \mathrm{~d}$ and $100 \mathrm{~d}$

Control, commercial feed; FB, whole faba bean; FBA, FB alcohol extract; FBW, FB water

extract; FBP, FB proteins; FBR, FB residues. A, total cholesterol (TC); B, triglycerides (TG); C, alkaline phosphatase (AKP); D, glutamic-pyruvic transaminase (GPT); E, glutamic oxalacetic transaminase (GOT); $\mathbf{F}$, peroxidase (POD). Different letters are significantly different $(P<$ $0.05)$. 

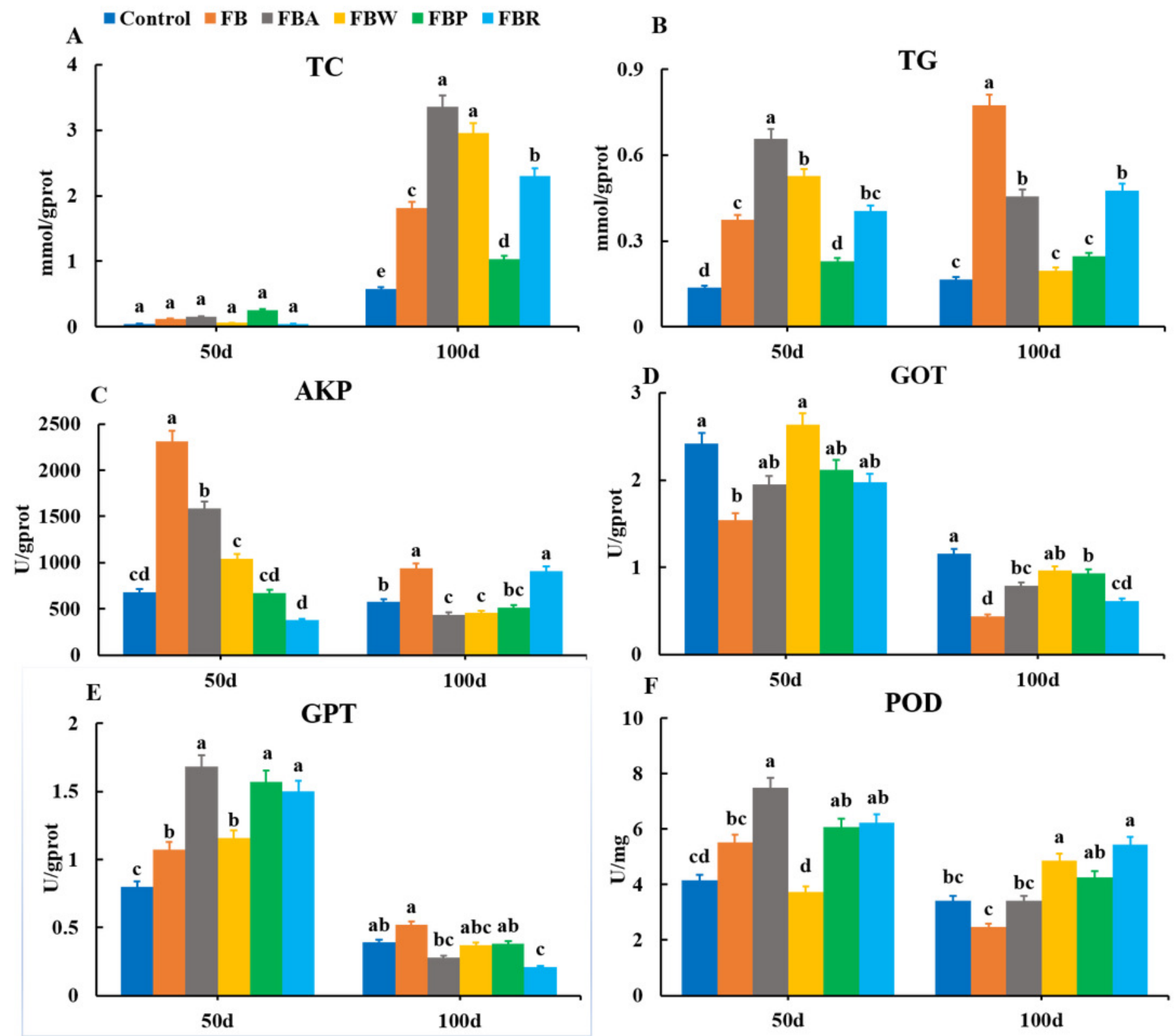


\section{Figure 4}

Fig. 4 Hepatopancreatic oxidative enzymes of grass carp on $50 \mathrm{~d}$ and $100 \mathrm{~d}$

Control, commercial feed; FB, whole faba bean; FBA, FB alcohol extract; FBW, FB water

extract; FBP, FB proteins; FBR, FB residues. A, superoxide dismutase (SOD); B, nicotinamide adenine dinucleotide (NADPH); C, nicotinamide adenine dinucleotide phosphate $\left(\mathrm{NADP}^{+}\right) ; \mathbf{D}$, photohydrogen peroxide $\left(\mathrm{H}_{2} \mathrm{O}_{2}\right)$; $\mathbf{E}$, Total glutathione (T-GSH); $\mathbf{F}$, oxidative glutathione (GGSH). Different letters are significantly different $(P<0.05)$. 


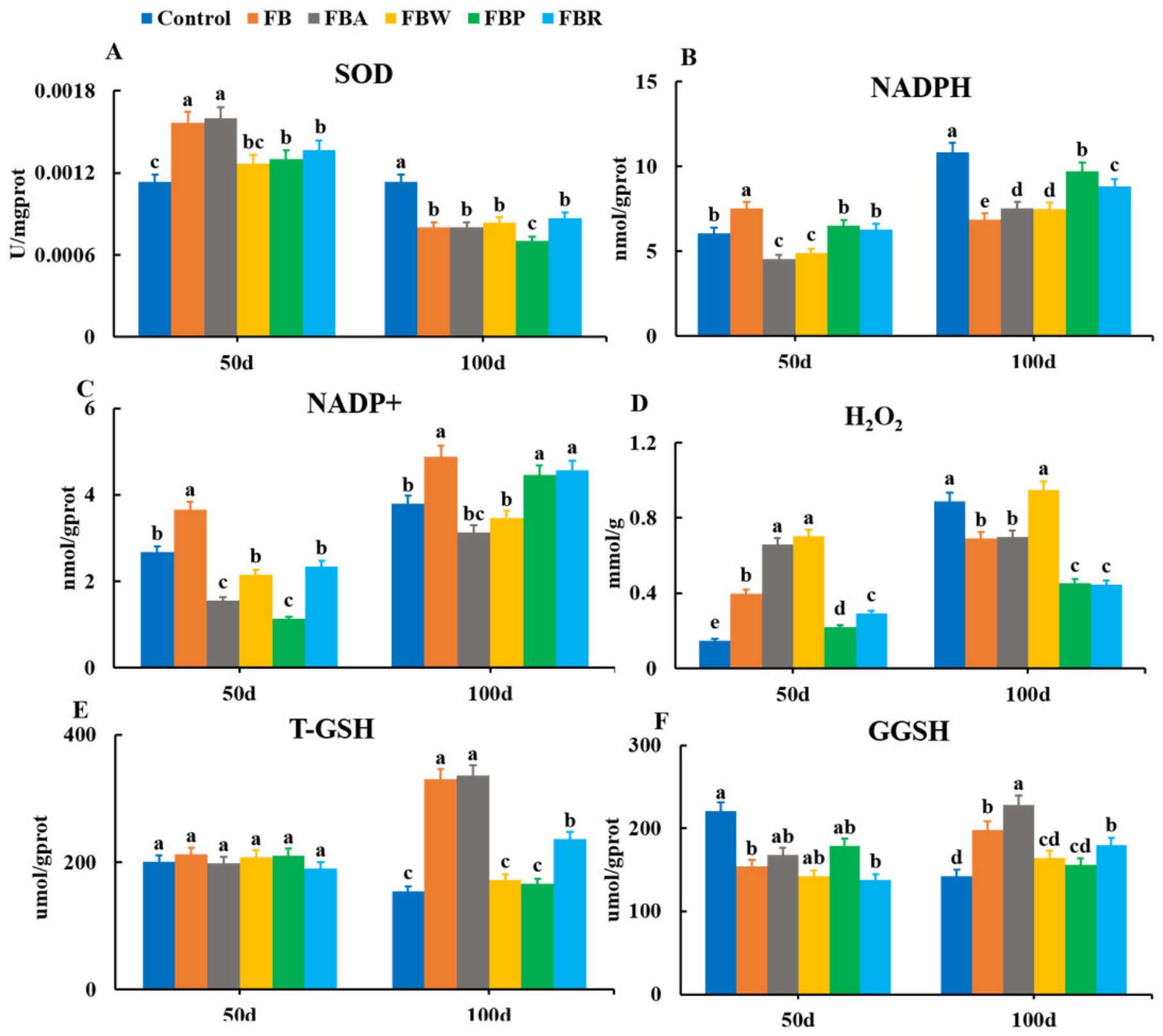




\section{Figure 5}

Fig. 5 Histological structure of hepatic tracts from grass carp on $100 \mathrm{~d}$

A, Control, commercial feed; B, FB, whole faba bean; C, FBA, FB alcohol extract; D, FBW, FB water extract; E, FBP, FB proteins; F, FBR, FB residues. H\&E, bar $=100 \mu \mathrm{m}$. Lipid vacuole (LV), central vein $(\mathrm{C})$, nucleus $(\mathrm{N})$, hepatic sinusoid $(\mathrm{HS})$, red cell $(\mathrm{RC})$ and cellular infiltration $(\mathrm{Cl})$.

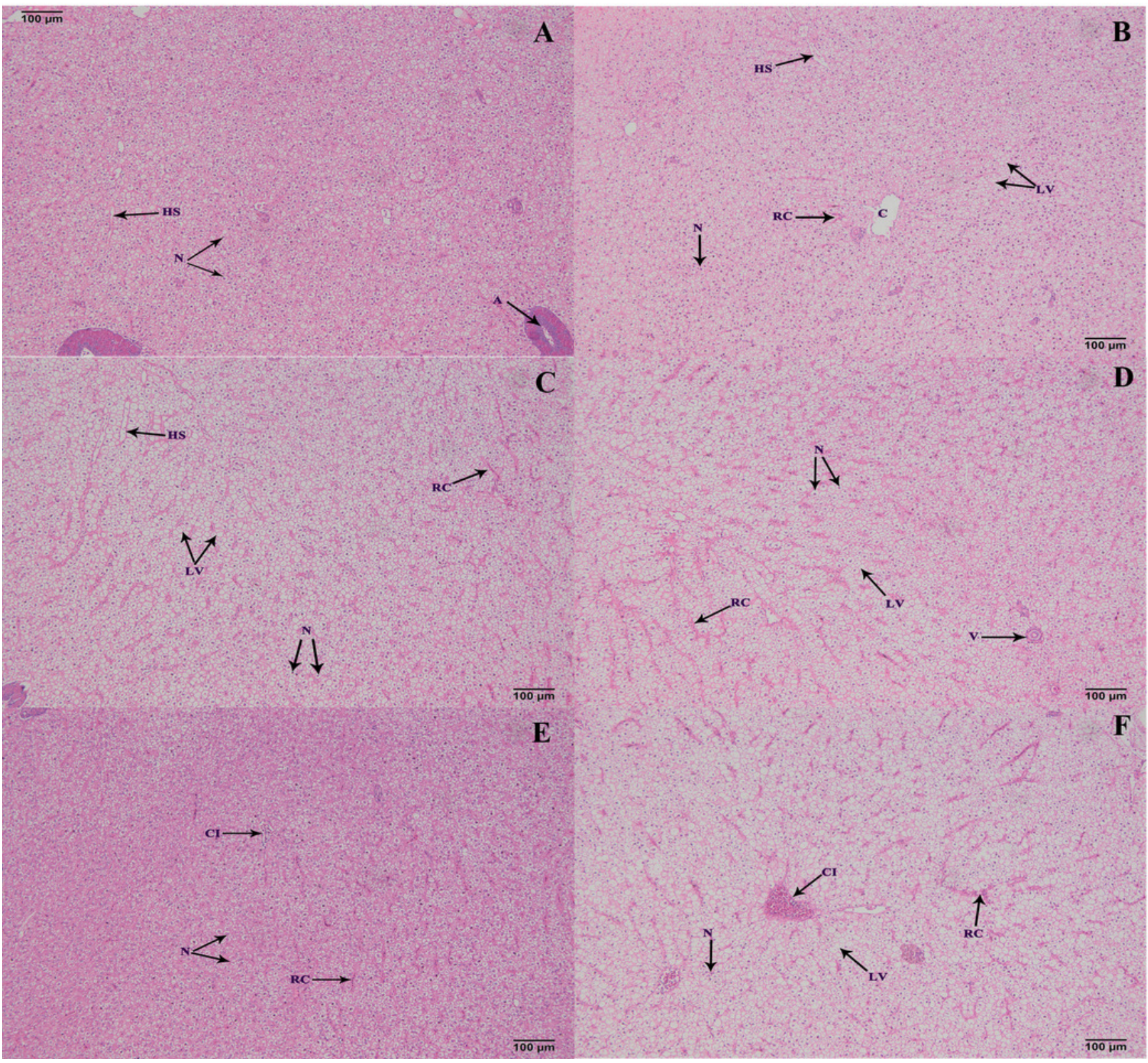

